\title{
GH enhances proliferation of human hepatocytes grafted into immunodeficient mice with damaged liver
}

\author{
Norio Masumoto ${ }^{1,2}$, Chise Tateno ${ }^{1,3}$, Asato Tachibana ${ }^{1,4}$, Rie Utoh , Yoshio Morikawa ${ }^{4}$, \\ Takashi Shimada $^{4}$, Hiroyuki Momisako ${ }^{1,2}$, Toshiyuki Itamoto ${ }^{2}$, Toshimasa Asahara ${ }^{2,3}$ and \\ Katsutoshi Yoshizato ${ }^{1,3,5}$ \\ ${ }^{1}$ Yoshizato Project, Cooperative Link of Unique Science and Technology for Economy Revitalization, Hiroshima Prefectural Institute of Industrial Science and \\ Technology, 3-10-32 Kagamiyama, Higashihiroshima, Hiroshima 739-0046, Japan \\ ${ }^{2}$ Division of Frontier Medical Science, Department of Surgery, Graduate School of Biomedical Sciences, Hiroshima University, 1-2-3 Kasumi, Minami-ku, \\ Hiroshima 734-8551, Japan \\ ${ }^{3}$ Hiroshima University Liver Project Research Center, 1-2-3 Kasumi, Minami-ku, Hiroshima 734-8551, Japan \\ ${ }^{4}$ PhoenixBio Co. Ltd, 3-4-1 Kagamiyama, Higashihiroshima, Hiroshima 739-0046, Japan \\ ${ }^{5}$ Developmental Biology Laboratory and Hiroshima University 21st Century COE Program for Advanced Radiation Casualty Medicine, Department of Biological \\ Science, Graduate School of Science, Hiroshima University, 1-3-1 Kagamiyama, Higashihiroshima, Hiroshima 739-8526, Japan \\ (Correspondence should be addressed to K Yoshizato; Email: katsutoshi.yoshizato@phoenixbio.co.jp) \\ (C Tateno and K Yoshizato are now at PhoenixBio Co. Ltd, 3-4-1 Kagamiyama, Higashihiroshima, Hiroshima 739-0046, Japan) \\ (R Utoh is now at Institute of Advanced Life and Medical Sciences, Tokyo Women's Medical College, Kawada-chou 8-6, Shinjuku-ku, Tokyo 162-8666, Japan)
}

\begin{abstract}
We investigated effects of human $(h) \mathrm{GH}$ on the proliferation of $h$-hepatocytes that had been engrafted in the liver of albumin enhancer/promoter driven-urokinase plasminogen activator transgenic/severe combined immunodeficiency disease (uPA/SCID) mice (chimeric mice). The $h$-hepatocytes therein were considered to be deficient in $\mathrm{GH}$, because $h \mathrm{GH}$ receptor ( $h \mathrm{GHR}$ ) is unresponsive to mouse $\mathrm{GH}$. Actually, $h$ IGF-1 was undetectable in chimeric mouse sera. The uPA/SCID mice were transplanted with $h$-hepatocytes from a 6-year (6Y)-old donor, and were injected with recombinant $h \mathrm{GH}(\mathrm{r} h \mathrm{GH})$. $\mathrm{r} h \mathrm{GH}$ stimulated the repopulation speed of $h$-hepatocytes; and up-regulated $h$ IGF-1, human signal transducers and activators of transcription (hSTAT) 3 ,
\end{abstract}

and cell cycle regulatory genes such as human forkhead box M1, human cell division cycle 25A, and human cyclin D1. To confirm the reproducibility of these effects of $\mathrm{r} h \mathrm{GH}$, similar experiments were run using $h$-hepatocytes from a 46 -year (46Y)-old donor. rh $\mathrm{GH}$ similarly enhanced their repopulation speed and up-regulated the expression of the abovetested genes, especially $h$ IGF- 1 and $h$ STAT1. The extent of the enhancement by $\mathrm{r} h \mathrm{GH}$ was much less than that in $6 \mathrm{Y}-$ hepatocyte-chimeric mice most probably due to the difference in GHR expression levels between the two donors. In conclusion, this study clearly demonstrated that $\mathrm{r} h \mathrm{GH}$ stimulates the proliferation of $h$-hepatocytes in vivo.

Journal of Endocrinology (2007) 194, 529-537

\section{Introduction}

Using rodents as experimental animals, it has been shown that differentiated hepatocytes can re-enter into the cell cycle when stimulated by growth factors, cytokines, and hormones (Taub 1996, Michalopoulos \& DeFrances 1997, Fausto 2000). Hepatocytes in culture usually lose their replication ability and normal phenotypes and, thus, have had limited usability in testing the effects of these factors on hepatocytes. In addition, their effects on human (h)-hepatocytes in vivo have not been studied due to the lack of a suitable animal model. Previously, we developed a method to yield humanized mice (chimeric mice) whose liver is mostly replaced with $h$-hepatocytes (Tateno et al. 2004). The $h$-hepatocytes were transplanted into immunodeficient mice with diseased liver, albumin enhancer/promoter driven-urokinase plasminogen activator transgenic/severe combined immunodeficiency disease (uPA/SCID) mice. The transplanted cells were engrafted in the liver, continuously replicated, and repopulated in the liver. The extent of repopulation was calculated as the ratio (replacement index, RI) of the $h$-hepatocyterepopulated area to the total examined area. Recent technological improvements enabled us to yield children's hepatocyte-chimeric mice with RI>96\%. The chimeric mice have been proven to be a useful animal model to examine biological and pathological features of $h$-hepatocytes in vivo (Tateno et al. 2004, Tsuge et al. 2005).

The regeneration capacity of rat liver decreases with age (Bucher et al. 1964, Stocker \& Heine 1971), which is coincident with the fact that serum concentrations of growth 
hormone (GH) and insulin-like growth factor 1 (IGF-1) diminish with age (Kelijman 1991, Corpas et al. 1993), suggesting the association of $\mathrm{GH}$ with liver regeneration. Actually, evidence has been accumulating that $\mathrm{GH}$ is involved in liver regeneration and accounts for an aspect of agedependent regenerative response of the liver in rodents (Krupczak-Hollis et al. 2003). However, the effects of GH on the growth of $h$-hepatocytes have not been studied in vivo at all yet. $h \mathrm{GH}$ is capable of stimulating rodent cells, whereas rodent GH cannot stimulate human cells because of its disability to bind to $h \mathrm{GH}$ receptors ( $h \mathrm{GHR} s$; Souza et al. 1995). Furthermore, it should be noted that $h \mathrm{GH}$ is not circulating in $h$-hepatocyte-chimeric mice, which indicates that $h$-hepatocytes in chimeric mice are in $\mathrm{GH}$-deficient conditions. These facts and considerations strongly suggest that a chimeric mouse will provide an opportunity to examine the effects of $h \mathrm{GH}$ on growth of $h$-hepatocytes in vivo.

In this study, we examined the effects of $h \mathrm{GH}$ on the proliferation of $h$-hepatocytes using chimeric mice. The treatment of chimeric mice with $h \mathrm{GH}$ increased the repopulation speed and RI of transplanted $h$-hepatocytes, and up-regulated the GH-related signaling molecules. The present study shows that a $h$-hepatocyte-chimeric uPA/SCID mouse is a useful in vivo model to examine the effects of growth factors, cytokines, and hormones on $h$-hepatocytes.

\section{Materials and Methods}

\section{Animals}

The uPA/SCID mice weighing 6.3-10.0 g were produced as previously described (Tateno et al. 2004). The zygosity of the $u P A$ transgene was determined by a multiplex PCR as previously described (Meuleman et al. 2003). Homozygous uPA/SCID mice were used as hosts throughout this study.

\section{Transplantation of hepatocytes and bromodeoxyuridine (BrdU)- labeling}

Cryopreserved $h$-hepatocytes from a 6-year-old Caucasian girl (6YG) and 46-year-old Caucasian man (46YM) respectively were purchased from In vitro Technologies (Baltimore, MD, USA) and thawed as previously described (Tateno et al. 2004). Trypan blue-exclusion test showed that the viability of 6YGand $46 \mathrm{YM}$-hepatocytes was $71 \cdot 5 \pm 4 \cdot 3 \%(n=3)$ and $72 \cdot 2 \pm$ $2 \cdot 3 \%(n=3)$ respectively. The $h$-hepatocytes $\left(7 \cdot 5\right.$ or $10 \cdot 0 \times 10^{5}$ viable cells) were transplanted into the inferior splenic pole of uPA/SCID mice at 20-30 days after birth, through a small leftflank incision (Tateno et al. 2004). BrdU (Sigma Chemical Co.) was intraperitoneally injected into chimeric mice at a dose of $50 \mathrm{mg} / \mathrm{kg}$ body weight at $1 \mathrm{~h}$ before killing. Histological sections were prepared from the liver and stained with antiBrdU antibodies as described below.

\section{rhGH treatment}

The 6YG- and 46YM-hepatocyte-chimeric mice were divided into two groups at 1 day post-transplantation; recombinant $h \mathrm{GH}$ (rhGH; Wako Pure Chemical Industries Ltd, Osaka, Japan)treated $\left(\mathrm{rhGH}^{+}\right.$, experimental) and -untreated $\left(\mathrm{r} h \mathrm{GH}^{-}\right.$, control) groups. $\mathrm{r} h \mathrm{GH}$ was dissolved in water and used for animal injection. Animals of experimental groups were daily administered from day 1 after transplantation to 1 day before the day of killing with $\mathrm{r} h \mathrm{GH}$ by subcutaneous injection at $2 \cdot 5 \mu \mathrm{g} / 10 \mu \mathrm{l}$ per g body weight.

\section{Measurement of human albumin (hAlb) and human IGF-1 concentrations in mouse blood or sera}

$h \mathrm{Alb}$ concentration in blood of a chimeric mouse is correlated with RI of transplanted hepatocytes (Tateno et al. 2004). Blood $(2 \mu \mathrm{l})$ was collected from the tail vein of $h$-hepatocytechimeric mice. The blood $h \mathrm{Alb}$ concentrations were determined with a latex agglutination assay (Eiken Immunochemical Laboratory, Tokyo, Japan) or a hAlb ELISA quantitation kit (Bethyl Laboratories Inc., Montgomery, TX, USA). As a measure of GH/IGF-1 signaling in the chimeric mice, serum human IGF-1 (hIGF-1) concentrations were determined using a hIGF-I ELISA kit (R\&D Systems Inc., Minneapolis, MN, USA).

\section{Immunohistochemistry and measurement of RI}

Frozen sections were prepared from chimeric livers, fixed in $-20{ }^{\circ} \mathrm{C}$ acetone for $5 \mathrm{~min}$ and incubated with anti-human cytokeratin 8 and $18(h \mathrm{CK} 8 / 18)$ antibodies (dilution, 1:25; MP Biomedicals, Aurora, OH, USA). The $h \mathrm{CK} 8 / 18$ antibodies reacted with $h$-hepatocytes but not with mouse $(m)$-hepatocytes. Formalin-fixed paraffin sections of chimeric livers were incubated with mouse anti-BrdU antibodies (dilution, 1:10; DakoCytomation, Glostrup, Denmark) and goat anti- $h$ Alb antibodies (dilution, 1:1000; Bethyl Laboratories). The primary antibodies were visualized with a Vectastain $\mathrm{ABC}$ kit (Vector Laboratories, Burlingame, CA, USA) or peroxidase- and dextran-conjugated anti-mouse immunoglobulins (Dako Envision +; DakoCytomation) with 3, 3'-diaminobenzidine (Sigma) as substrates. The sections were counterstained with Mayer's hematoxylin. RI was calculated as the ratio of area occupied by $h \mathrm{CK} 8 / 18$-positive hepatocytes to the entire area examined on immunohistochemical sections of six lobes (Tateno et al. 2004). The ratios of BrdU-positive nuclei to $h \mathrm{Alb}$-positive $h$-hepatocytes were determined by counting at least 1000 cells in 10 to 15 randomly selected vision fields in sections.

\section{Quantification of $m R N A$ in the livers of chimeric mice}

Total RNAs were purified from liver tissues by an RNeasy mini kit (Qiagen). Using $1 \mu \mathrm{g}$ total RNA by PowerScript reverse transcriptase (Clontech Inc.) and Random Primer oligonucleotides (Invitrogen Corp.), cDNAs were 
synthesized according to the manufacturer's instruction. The mRNAs of genes shown in Table 1 were quantified in the liver tissues of chimeric mice by real-time RT-PCR (Tateno et al. 2004). Genes were amplified with a set of gene-specific primers shown in Table 1 and SYBR Green PCR mix (Applied Biosystems, Tokyo, Japan) in PRISM 7700 Sequence Detector (Applied Biosystems). We confirmed that these primers for $h$-genes amplified the $h$ - but not the $m$-genes. Real-time RT-PCR was performed as follows: initial denaturation step at $95^{\circ} \mathrm{C}$ for $10 \mathrm{~min}$, followed by 40 cycles at $95^{\circ} \mathrm{C}$ for $15 \mathrm{~s}$ and 60 or $62^{\circ} \mathrm{C}$ for $1 \mathrm{~min}$. All data were treated as previously described (Livak \& Schmittgen 2001). The expression levels of the tested genes were normalized to the expression level of human glyceraldehyde 3-phosphate dehydrogenase $(h G A P D H)$ gene and human hypoxanthine phosphoribosyltransferase 1 (hHPRT-1) gene.

\section{Statistical analysis}

Data were analyzed with StatView, 5.0 (SAS Institute Inc., Cary, NC, USA). Results are shown as the mean \pm s.E.M. or S.D., and the significance of the difference between two groups under comparison was analyzed by Student's $t$-test when data were normally distributed and otherwise by Welch's test.

\section{Results}

\section{Relationship of engraftment with repopulation of h-hepatocytes}

In this study, we aimed to quantitatively assess the effect of $\mathrm{r} h \mathrm{GH}$ on the extent of repopulation of $h$-hepatocytes in chimeric mice. It was considered that the number of engrafted $h$-hepatocytes depends on the number of the injected cells and affects the time length to reach the final (maximal) RI. Thus, we first examined the relationship between the number of the originally engrafted $h$-hepatocytes and that of the maximally repopulated $h$-hepatocytes, assuming that there is a linear relationship between the occupancy rate of $h$-hepatocytes after transplantation and the number of originally engrafted $h$-hepatocytes before the occupancy rate reaches the maximum when the repopulating $h$-hepatocytes terminate the proliferation (the saturation phase of the repopulation). Ten and 27 uPA/SCID mice were transplanted with $7 \cdot 5$ and $10 \cdot 0 \times 10^{5} 6$ YG-hepatocytes/ animal respectively. All of the animals were successfully engrafted with $h$-hepatocytes. Blood $h$ Alb levels were determined at 19-22 days post-transplantation as a measure of the number of the originally engrafted $h$-hepatocytes, and at 55-61 days as a measure of the number of the repopulated $h$-hepatocytes. The levels of '19-22 day'-group ( $\left.h \mathrm{Alb}_{19-22}\right)$ are plotted against those of '55-61 day'-group ( $h \mathrm{Alb}_{55-61}$; Fig. 1). The graph consisted of two regions, a near linear region in which $h \mathrm{Alb}_{55-61}$ increased with $h \mathrm{Alb}_{19-22}$ in a near linear fashion and a region of near plateau in which the increase of $h \mathrm{Alb}_{19-22}$ did not meaningfully increase $h \mathrm{Alb}_{55-61}$. It can be said that the plateau level $(6-10 \mathrm{mg} / \mathrm{ml})$ represented the maximal level (the maximal RI) of the occupancy of $h$-hepatocytes in the experimental conditions we adopted. In the case of $7 \cdot 5 \times 10^{5}$ cell transplantation, most chimeric mice showed $h \mathrm{Alb}_{19-22}<0.5 \mathrm{mg} / \mathrm{ml}$, and $h \mathrm{Alb}_{55-61}$ was increased with the increase of $h \mathrm{Alb}_{19-22}$. This result supported the above assumption that $h$-hepatocytes near lineally increased in number with the increase in the number of the originally engrafted $h$-hepatocytes and they did not reach the maximal repopulation state until 55-61 days post-transplantation. However, it should be noted here that the $h \mathrm{Alb}$ level does not correctly reflect the number of the repopulated $h$-hepatocytes as we showed in the previous study (Tateno et al. 2004) and also in the present study.

In contrast, in the case of $10 \cdot 0 \times 10^{5}$ cell transplantation, most of the chimeric mice showed $h \mathrm{Alb}_{19-22}>0.5 \mathrm{mg} / \mathrm{ml}$ and reached the plateau level $(>6 \mathrm{mg} / \mathrm{ml})$ at $55-61$ days, suggesting that there is an appropriate number of $h$-hepatocytes to be injected to obtain a high-engraftment rate (the number ratio of the engrafted $h$-hepatocytes to the injected $h$-hepatocytes). It is considered that the number of $7 \cdot 5 \times 10^{5}$ was smaller than this appropriate number. It appeared in $10 \cdot 0 \times 10^{5} \mathrm{~h}$-hepatocyte transplantation experiments that the proliferation of

Table 1 Oligonucleotide primers used in PCR amplification of growth hormone (GH)-related genes

Forward primer $\left(5^{\prime}-3^{\prime}\right)$

\section{Gene \\ $h G H R$ \\ hIGF-I \\ hSTAT1 \\ hSTAT3 \\ hFoxM1 \\ $h C d c 25 A$ \\ hcyclin B1 \\ hcyclin D1 \\ $h C d k 1$ \\ hCdk2 \\ hGAPDH}

hHPRT1

\author{
TCACTCAAGGTTGAATCACAC \\ GCTTCCGGAGCTGTGATCTAA \\ TTGCAGAACAGAGAACACGAGA \\ GACCAACAATCCCAAGAATGTA \\ GCATCTACTGCCTCCСTGTG \\ CAAAGAGGAGGAAGAGCATGTC \\ CCTGATGGAACTAACTATGTTG \\ TGTGAAGTTCATTTCCAATCCG \\ AAACTACAGGTCAAGTGG \\ ACAAGTTGACGGGAGAGGTG \\ CCACCTTTGACGCTGGG \\ TGGTCAGGCAGTATAATC
}

Reverse primer $\left(5^{\prime}-3^{\prime}\right)$

TCACATCAAGGTTGAATCACAC
GCTGACTTGGCAGGCTTG
CATTCTGGGTAAGTTCAGTGAC
AATAATTCACACCAGGTCCCAA
GAGGAGTCTGCTGGGAACG
CCAGGGATAAAGACTGATGAAGAG
CATGTGCTTTGTAAGTCCTTGA
CTGGAGAGGAAGCGTGTGAG
GGGATAGAATCCAAGTATTTCTTCAG
CAGAAATTCAAAAACCAGGTAGAGT
CATACCAGGAAATGAGCTTGACA
CAGTTTAGGAATGCAGCA




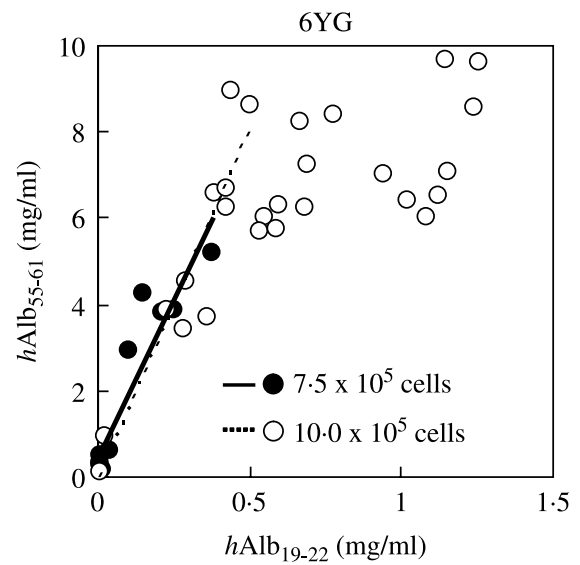

Figure 1 Relationship between hAlb concentrations in early and late time points after transplantation. uPA/SCID mice were transplanted with $7 \cdot 5$ (closed circles) and $10 \cdot 0 \times 10^{5}$ 6YGhepatocytes (open circles). hAlb levels at 19-22 days posttransplantation ( $h \mathrm{Al} \mathrm{b}_{19-22}$ ) were plotted against those at 55-61 days $\left(h \mathrm{Alb} \mathrm{b}_{5-61}\right)$. The $h \mathrm{Alb}_{55-61}$ in the $7 \cdot 5 \times 10^{5}$ cell-transplantation experiment were lineally correlated with those at the $h \mathrm{Alb}_{19-22}$ $\left(r^{2}=0 \cdot 86\right.$, solid line). The $h \mathrm{Alb}_{55-61}$ in the $10 \cdot 0 \times 10^{5}$ celltransplantation experiment were also lineally correlated with $h \mathrm{Alb}_{19-22}$ in the range $<0.5 \mathrm{mg} / \mathrm{ml}$ of $h \mathrm{Alb}\left(r^{2}=0 \cdot 87\right.$, dotted line $)$.

$h$-hepatocytes terminated around 60 days post-transplantation when the $h \mathrm{Alb}$ level reached $6 \mathrm{mg} / \mathrm{ml}$ irrespective of $h \mathrm{Alb}_{19-22}$, probably due to the contact inhibition among the $h$-hepatocytes, the toxicity of $h$-hepatocytes for the mouse when $h \mathrm{Alb}$ exceeded $6 \mathrm{mg} / \mathrm{ml}$, and other yet unknown reasons. In $10 \cdot 0 \times 10^{5}$ cell-transplantation experiments, there were several mice that showed $h \mathrm{Alb}_{19-22}<0.5 \mathrm{mg} / \mathrm{ml}$. An apparent similar relationship between $h \mathrm{Alb}_{19-22}$ and $h \mathrm{Alb}_{55-61}$ was seen in these animals as in $7.5 \times 10^{5} h$-hepatocyte transplantation experiments. Therefore, we empirically concluded that $h$-hepatocytes increased in number in an apparently quasilinear fashion after the engraftment from $h \mathrm{Alb}_{19-22}<0.5 \mathrm{mg} / \mathrm{ml}$ to $h \mathrm{Alb}_{55-61}<6 \mathrm{mg} / \mathrm{ml}$. Thus, we utilized chimeric mice with $h \mathrm{Alb}_{19-22}<0.5 \mathrm{mg} / \mathrm{ml}$ for examining the effects of $h \mathrm{GH}$ on the proliferation of $h$-hepatocytes in the following experiments.

It has been generally recognized that $h \mathrm{GH}$ is capable of stimulating rodent cells, whereas rodent GHs are not able to bind to GHRs on $h$-hepatocytes (Souza et al. 1995). Six uPA/ SCID mice were transplanted with $10 \cdot 0 \times 10^{5}$ 6YG-hepatocytes/mouse. Half of them were treated with $\mathrm{r} h \mathrm{GH}$. The blood $h \mathrm{Alb}$ levels were monitored throughout the experimental period (up to 55 days) after transplantation (Fig. 2A). The concentrations of $h \mathrm{Alb}$ rapidly increased and exceeded $0.5 \mathrm{mg} /$ $\mathrm{ml}(0 \cdot 5-1 \cdot 36 \mathrm{mg} / \mathrm{ml})$ around 20 days post-transplantation in all mice irrespective of the treatment of $\mathrm{r} h \mathrm{GH}$ and reached over $6 \mathrm{mg} / \mathrm{ml}$ around 50 days after transplantation. There were no differences in $h$ Alb levels between $r h \mathrm{GH}^{-}$and $\mathrm{r} h \mathrm{GH}^{+}$chimeric mice. At the end of this experiment, mice were killed for determining RI on immunohistological sections prepared from their liver tissues (Fig. 2B). Also, there were no differences in RIs between the two groups. Serum $h \mathrm{IGF}-1$ levels were determined
A

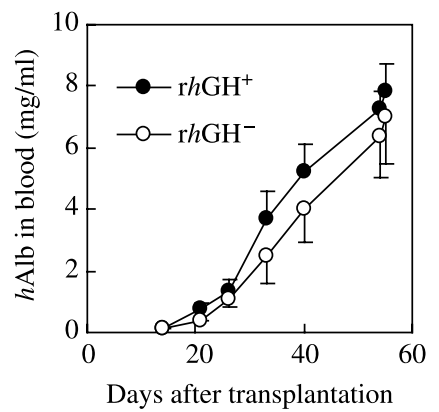

Figure 2 Repopulation of $h$-hepatocytes in uPA/SCID mice. Each uPA/SCID mouse was transplanted with $10 \cdot 0 \times 10^{5}$ 6YG-hepatocytes. Animals in $\mathrm{rhGH}^{+}$group were daily injected with $\mathrm{rhGH}$ and $h$ Alb concentrations in host blood were monitored (A). Rls of $\mathrm{rhGH}^{-}$(open bar)- and $\mathrm{rhGH}^{+}$6YG-chimeric mice (closed bar) were determined at 55 days post-transplantation (B). Values represent the mean \pm S.E.M. of three different mice.

for mice from $\mathrm{r} h \mathrm{GH}^{-}$and $\mathrm{r} h \mathrm{GH}^{+}$groups. $h \mathrm{IGF}-1$ was not detected in the animals of $\mathrm{r}_{\mathrm{GH}}{ }^{-}$groups whose $h \mathrm{Alb}$ concentrations were $8 \cdot 2 \pm 1 \cdot 1 \mathrm{mg} / \mathrm{ml}(n=3)$. In contrast $h \mathrm{IGF}-1$ was detectable $(11.9 \pm 11.2 \mathrm{mg} / \mathrm{ml}, n=3)$ in mice of $\mathrm{rhGH}^{+}$groups whose $h \mathrm{Alb}$ concentrations were $7 \cdot 9 \pm$ $1.9 \mathrm{mg} / \mathrm{ml}(n=3)$. Thus, the absence of $h \mathrm{IGF}-1$ in sera of mice in $\mathrm{rhGH}^{-}$groups is explainable at least in part by assuming that $h$-hepatocytes did not respond to $m \mathrm{GH}$ in the chimeric mice, and when $r h \mathrm{GH}$ was given, $h$-hepatocytes responded to it and up-regulated $h \mathrm{IGF}-1$ expression.

\section{Enhancement of the repopulation of h-hepatocytes by $h \mathrm{GH}$}

Nine and eight uPA/SCID mice were transplanted with $7 \cdot 5 \times$ $10^{5} 6 \mathrm{YG}$ - and $10 \cdot 0 \times 10^{5} 46 \mathrm{YM}$-hepatocytes/animal, then five and four of them were treated with $\mathrm{r} h \mathrm{GH}$ respectively. Chimeric mice with both 6YG- and 46YM-hepatocytes showed variable $h$ Alb levels, which were $0 \cdot 01-0.6$ and $0 \cdot 0005-0 \cdot 3 \mathrm{mg} / \mathrm{ml}$ at 20 days post-transplantation respectively. Three $\mathrm{rhGH}^{+}$and $\mathrm{r} h \mathrm{GH}^{-}$mice with $0 \cdot 01-0 \cdot 05 \mathrm{mg} / \mathrm{ml} h \mathrm{Alb}$ each were selected from $6 \mathrm{YG}$ - and $46 \mathrm{YM}$-chimeric mice. The $\mathrm{r} h \mathrm{GH}$ enhanced the increase of $h \mathrm{Alb}$ levels in both groups (Fig. 3). $\mathrm{r}_{\mathrm{GH}}{ }^{-}$animals slowly increased the values after 20 days post-transplantation, whereas $\mathrm{r} h \mathrm{GH}^{+}$mice rapidly increased them in $6 \mathrm{YG}$-chimeric mice (Fig. 3A). The transplanted cells in $\mathrm{rhGH}^{-}$46YM-mice also slowly grew as in 6YG-mice (Fig. 3B). The rhGH also accelerated the repopulation in these mice, though its effect was considerably lower when compared with 6YG-hepatocyte mice.

The chimeric mice transplanted with 6YG- and 46YMhepatocytes shown in Fig. 3A and B respectively were killed at 70 and 76 days post-transplantation for histological examinations respectively. There were no differences between $\mathrm{r} h \mathrm{GH}^{+}$ and $\mathrm{r} h \mathrm{GH}^{-}$mice in body weight and liver size at the time of killing. $h$-Hepatocytes were immunohistochemically identified as $h \mathrm{CK} 8 / 18$-positive cells (Fig. 3C through F). Distributions of the immunopositive 6YG- and 46YM-cells in ${\mathrm{r} h \mathrm{GH}^{-}}^{-}$animals are shown in Fig. 3C and E respectively. $h$-Hepatocyte colony 

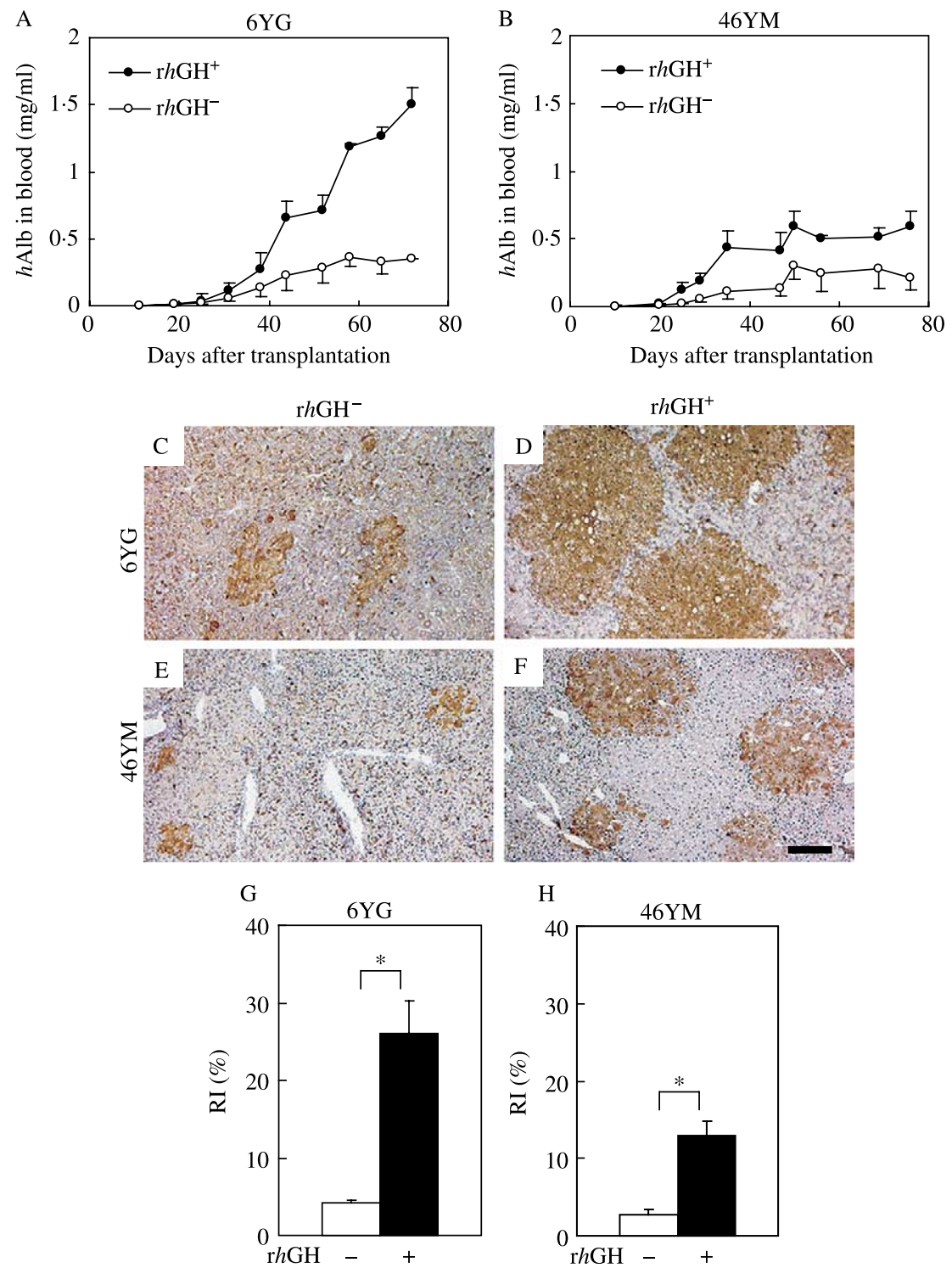

Figure 3 Effects of $h \mathrm{GH}$ on repopulation of $h$-hepatocytes. 6YG $\left(7 \cdot 5 \times 10^{5}, \mathrm{~A}\right)$ - and $46 \mathrm{YM}$ $\left(10 \cdot 0 \times 10^{5}, \mathrm{~B}\right)$-hepatocytes were transplanted into each of uPA/SCIDmice and treated with rhGH as in Fig. 2. $h$ Alb concentrations were monitored once a week. Solid and open circles show $r h \mathrm{GH}^{+}$and $\mathrm{rhGH}^{-}$mice respectively (C through $\mathrm{F}$ ). Histological sections were prepared from six liver lobes of 6YG-chimeric mice at 70 days post-transplantation (C and D) and from those of $46 \mathrm{YM}$-chimeric mice at 76 days post-transplantation ( $\mathrm{E}$ and $\mathrm{F}$ ). The sections were stained with anti-hCK8/18 antibodies. Sections ' $\mathrm{C}$ and $\mathrm{E}^{\prime}$ and ' $\mathrm{D}$ and $\mathrm{F}^{\prime}$ were from $r h \mathrm{GH}^{-}$and $\mathrm{rhGH}^{+}$mice respectively. The cytoplasm of hCK8/18-positive $h$-hepatocytes is stained brown. Scale bar in F: $20 \mu \mathrm{m}(\mathrm{G}$ and $\mathrm{H})$. RI was calculated as the ratio of the brown colored areas to the examined total ones for 6YG- $(\mathrm{G})$ and 46YM-chimeric mice $(\mathrm{H})$. Open and closed bars show $r h \mathrm{GH}^{-}$and $r h \mathrm{GH}^{+}$mice respectively. Values represent the mean \pm s.E.M. of three different mice. Asterisks indicate significant differences $\left({ }^{*} P<0 \cdot 05\right.$, Student's $t$-test).

sizes were larger in 6YG- than in 46YM-hepatocytes. The size was greatly increased in $\mathrm{r} h \mathrm{GH}^{+}$mice for both 6YG- (Fig. 3D) and 46YM-hepatocytes (Fig. 3F). $h \mathrm{GH}$ increased RI $\sim 6 \cdot 2$ - and 4.8-fold in 6YG-and 46YM-hepatocyte-chimeric mice respectively (Fig. $3 \mathrm{G}$ and $\mathrm{H}$ ).
Effects of th GH on DNA synthesis of h-hepatocytes in chimeric mice

We investigated whether $r h \mathrm{GH}$ stimulated the DNA synthesis of $h$-hepatocytes in chimeric mice. uPA/SCID mice were transplanted with 6YG- or 46YM-hepatocytes, injected with 
rhGH, and were exposed with BrdU before killing at 2 weeks post-transplantation. BrdU-positive $h$-hepatocytes were often distributed in the peripheral regions of the colonies (Fig. 4A for 6YG-hepatocytes). The BrdU-labeling index of $6 \mathrm{YG}^{-}$ hepatocytes in $\mathrm{rh} \mathrm{GH}^{+}$mice was $2 \cdot 2$-fold higher $(P<0 \cdot 05)$ than that in $\mathrm{rhGH}^{-}$mice (Fig. 4B), indicating that $\mathrm{GH}$ induced the entry of $h$-hepatocytes into the S-phase of the cell cycle. The index of $\mathrm{r} h \mathrm{GH}^{+}$46YM-mice was 1-4-fold higher than that of $\mathrm{rhGH}^{-}$ones, but the difference was not significant.

\section{Expression of hepatocyte growth-associated genes in chimeric livers}

Previously, we showed the BrdU-labeling index of $h$ hepatocytes (9-month-old Caucasian boy) in chimeric mice at 1,3 , and 5 weeks post-transplantation was $\sim 9,5$, and $2 \%$

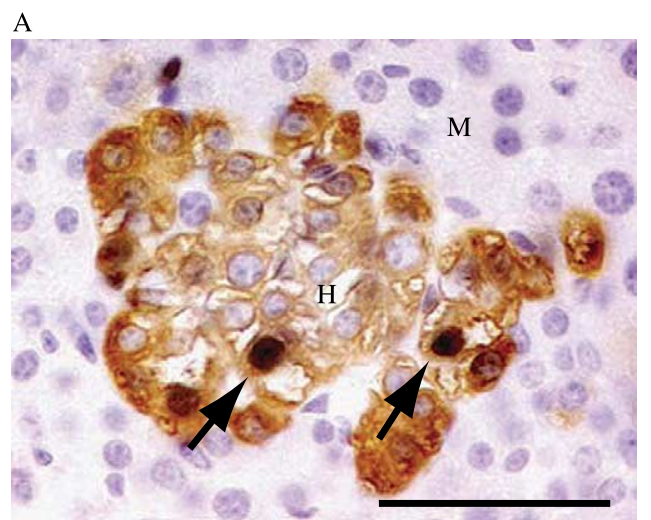

B

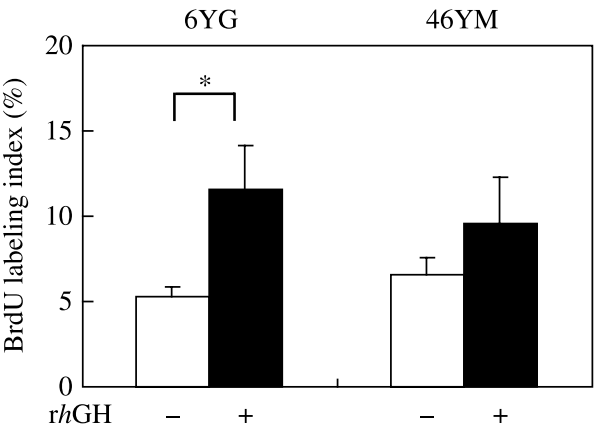

Figure $4 \mathrm{BrdU}$ incorporation in the liver of chimeric mice. 6YGand 46YM-hepatocytes were transplanted into uPA/SCIDmice, and they were treated with $\mathrm{rhGH}$ as in Fig. 2. They were injected with $\mathrm{BrdU}$ at 2 weeks post-transplantation, and killed $1 \mathrm{~h}$ later. A. The liver sections from a $6 \mathrm{YG}$-chimeric mouse were subjected to double immunostaining with BrdU and hAlb. hAlb-positve $h$-hepatocytes have brown cytoplasm. BrdU-positive $h$-hepatocytes have dark brown nuclei (arrows). $\mathrm{M}$ and $\mathrm{H}$ indicate regions of $m$ - and $h$ hepatocytes. Scale bar: $50 \mu \mathrm{m}$. B. BrdU-labeling index was calculated as the ratio of BrdU-positive nuclei to all the counted nuclei. Solid and open bars show $\mathrm{rhGH}^{+}$and $\mathrm{rhGH}^{-}$mice respectively. Values represent the mean \pm s.D. of experiments with 6 YG- mice $(n=3)$ and $46 \mathrm{YM}$-mice $(n=4)$. Asterisks indicate significant differences at $* P<0 \cdot 05$ (Student's $t$-test). respectively, and thereafter gradually decreased to $<0.5 \%$ at 10-11 weeks (Emoto et al. 2005). Taking the present results shown in Fig. 4 and the above cited previous ones together, we considered that transplanted $h$-hepatocytes become most proliferative around 1 week post-transplantation, and, thus, hepatocyte growth-associated genes become activated then. However, there were not enough $h$-hepatocytes yet to yield sufficient RT-PCR amplification. Thus, we examined the effect of $\mathrm{r} h \mathrm{GH}$ on the expression of hepatocyte growthassociated genes in $h$-hepatocytes of chimeric livers at 2 weeks point post-transplantation. Chimeric mice were treated with rhGH as in Fig. 4 and were killed at 2 weeks posttransplantation to determine mRNA levels of 10 genes by real-time RT-PCR: $h \mathrm{GHR}, h \mathrm{IGF}-1$, human signal transducers and activators of transcription (hSTAT) 1, hSTAT3, human forkhead box ( $h$ Fox) M1, human cell division cycle $(h \mathrm{Cdc})$ 25A, h-cyclin B1, $h$-cyclin D1, human cyclindependent kinases $(h \mathrm{Cdk}) 1$, and $h C d k 2$. The expression levels were normalized to that of $h G A P D H$ gene. The ratios of the expression under $r h \mathrm{GH}^{+}$to that under $r h \mathrm{GH}^{-}$are depicted as graphs for 6YG- (Fig. 5A) and 46YM-mice (Fig. 5B). rhGH did markedly increase $h \mathrm{IGF}-1 \mathrm{mRNA}$ in both 6YG- (Fig. 5A) and 46YM-hepatocyte-chimeric mice (Fig. 5B; $P<0 \cdot 05$, Student's t-test or Welch's test). The stimulation rate $(9 \cdot 1$-fold) in 6YG-hepatocyte mice was much higher than that $(2 \cdot 6$-fold $)$ in 46YM-hepatocyte ones. The effects of $\mathrm{r} h \mathrm{GH}$ were generally much prominent in chimeric mice bearing 6YG-hepatocytes as compared with that in those bearing 46YM-ones. In 6YG-hepatocytechimeric mice, rh $\mathrm{GH}$ significantly increased the expressions of mRNAs of $h \mathrm{STAT} 3, h$ FoxM1, $h \mathrm{Cdc} 25 \mathrm{~A}$, and $h$-cyclin D1 $(P<0 \cdot 05$, Student's $t$-test, Fig. 5A). The expression levels for mRNAs of $h \mathrm{STAT} 1, h$-cyclin B1, $h \mathrm{Cdk} 1$, and $h \mathrm{Cdk} 2$ were higher in the $r h \mathrm{GH}^{+}$- group than in $\mathrm{rGH}^{-}$group in 6YGhepatocyte-chimeric mice, although the difference in the ratio between the two groups was not significant. Similarly, mRNAs of $h$ STAT 1 and $h$ STAT3 were induced by $r h \mathrm{GH}$ in 46YM-hepatocyte-chimeric mice, although the difference was not significant (Fig. 5B). In contrast to the expression in $6 \mathrm{YG}$-chimeric mice, $\mathrm{r} h \mathrm{GH}$ did not induce mRNAs of $h$ FoxM1, $h$ Cdc25A, $h$-cyclin B1, $h$-cyclin D1, $h \mathrm{Cdk} 1$, and $h \mathrm{Cdk} 2$ in 46YM-chimeric mice (Fig. 5B). 6YG-hepatocytes expressed $h \mathrm{GHR}$ mRNA at a $19 \cdot 5$-fold higher level than 46YM-hepatocytes in $\mathrm{r}_{\mathrm{GH}}{ }^{-}$group, suggesting differences in the responsiveness of these growth-related genes to $\mathrm{r} h \mathrm{GH}$ might be due to the difference in GHR expression levels between the two donors. Similar results were obtained when the data were normalized by $h$ HPRT-1 as another housekeeping gene.

\section{Discussion}

Hepatocytes of uPA/SCID mice undergo severe injury and, thus, genes of cytokines involved in liver regeneration are activated (Mars et al. 1995, Michalopoulos \& DeFrances 
A

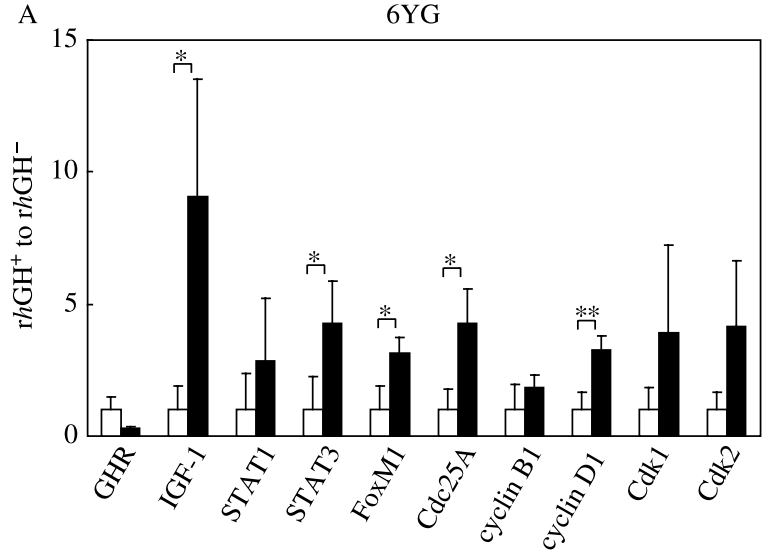

B

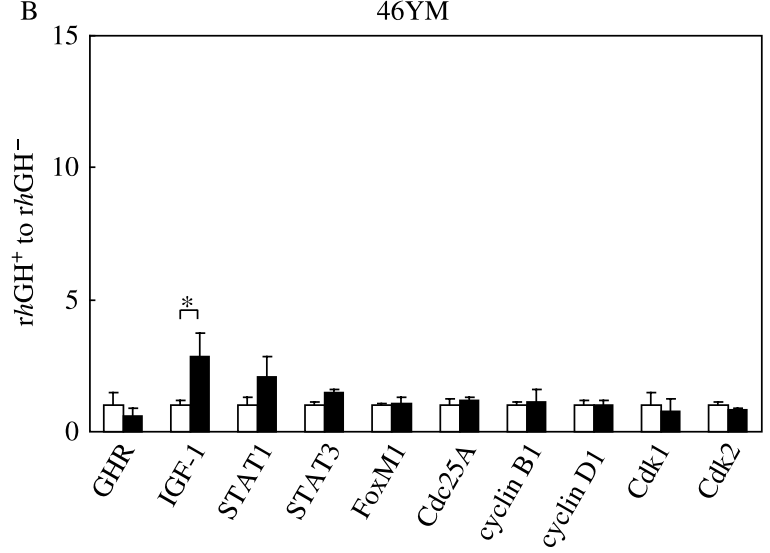

Figure 5 Expression of GH-related genes in chimeric mouse liver. Chimeric mice were yielded by transplanting 6YG- (A) and 46YMhepatocytes (B), and treated with rhGH as in Fig. 2. The animals were killed at 2 weeks after transplantation. RNA was extracted from livers and used for determining the amount of mRNAs of ten genes, hGHR, hIGF-1, hSTAT1, hSTAT3, hFoxM1, $h$ Cdc25A, $h$ cyclin B1, $h$-cyclin D1, $h \mathrm{Cdk} 1, h \mathrm{Cdk} 2$, and $h \mathrm{GAPGH}$ by real-time quantitative RT-PCR. Each data was divided by the data of $h \mathrm{GAPDH}$. The graphs represent the ratio of the $\mathrm{rGH}^{+}$to the $r h \mathrm{GH}^{-}$levels. Open and closed bars show $r h \mathrm{GH}^{-}$and $r h \mathrm{GH}^{+}$ mice respectively. Values represent the mean \pm s.D. Asterisks indicate significant differences at ${ }^{*} P<0 \cdot 05$ and ${ }^{* *} P<0 \cdot 01$.

1997). GH is one of such stimulators of liver regeneration in rodents (Krupczak-Hollis et al. 2003, Pennisi et al. 2004). Krupczak-Hollis et al. (2003) showed that GH promoted the proliferation of hepatocytes upon the partial hepatectomy in mice, which was mediated through activation of FoxM1B gene. Transgenic mice bearing $\mathrm{GH}$-antagonist genes showed an incomplete liver regeneration and a reduced renewal rate of hepatocytes (Pennisi et al. 2004), suggesting a critical role of $\mathrm{GH}$ in liver regeneration. Regeneration-associated proliferation of hepatocytes in mice was impaired with a liver-specific IGF-1 receptor gene knockout (Desbois-Mouthon et al. 2006). In contrast to such abundant studies on rodents, there have been no studies on the effects of GH on $h$-hepatocytes in vivo. We undertook the present study assuming that a chimeric mouse will provide an opportunity to examine the effects of $\mathrm{r} h \mathrm{GH}$ on proliferation of $h$-hepatocytes in vivo, because we considered that $h$-hepatocytes in chimeric mice are in GH-deficient conditions. This consideration was supported by the present study because we showed that $h$ IGF-1 was actually undetectable in the chimeric mouse sera. We expected that $\mathrm{r} h \mathrm{GH}$ treatment might enhance the proliferation of $h$-hepatocytes in uPA/SCID mice. Chimeric mice were yielded bearing $h$-hepatocytes from two donors whose sex and age were different, 6YG and 46YM, and were treated with $\mathrm{r} h \mathrm{GH}$. As a result, we were able to demonstrate for the first time that $\mathrm{r} h \mathrm{GH}$ stimulates the proliferation of $h$-hepatocytes in vivo. This conclusion was reproducibly obtained from the two independent experiments using hepatocytes from different donors, although the extent of the stimulation was much higher for 6YG-hepatocytes than for 46YM-hepatocytes. This difference of GH-stimulation between the two donors might be explainable by the difference of GHR-expression level between them as shown in this study.

Studies on the molecular mechanisms of the action of GH are currently progressing in rodents. c-fos gene is an immediate early responsive gene to $\mathrm{GH}$, which is mediated by STAT1 and STAT3 (Gronowski \& Rotwein 1994, Gronowski et al. 1995, Herrington et al. 2000). Our study showed that $\mathrm{r} h \mathrm{GH}$ increased the expression of $h$ STAT1 and $h$ STAT3 mRNAs in $h$-hepatocytes in chimeric mice. GH stimulates the growth of target cells through GHRs and its endocrine IGF-1 (Daughaday \& Rotwein 1989). GH stimulates the synthesis and the secretion of IGF-1 by hepatocytes (Sjogren et al. 1999, Yakar et al. 1999). Secreted IGF-1 binds to the IGF-IR, which activates the expression of cell cycle-related genes such as cyclin D1 through ERK pathway (Desbois-Mouthon et al. 2006). Our present study showed that $\mathrm{r} h \mathrm{GH}$ enhanced the expression of $h \mathrm{IGF}-\mathrm{I}$ and cyclin D1 mRNAs in the liver of chimeric mice. Therefore, it is concluded that GH stimulates the growth of $h$-hepatocytes through activating GH/IGF-I/IGF-IR/ERK signaling. These results suggest that the stimulation of growth of hepatocytes by GH is induced through similar mechanisms in both rodents and humans. Studies remain to be done on the protein phosphorylation or the activation of the signaling cascades after the $\mathrm{r} h \mathrm{GH}$-stimulation using currently developed $h$-hepatocyte-chimeric mice.

It was shown in rodents that GH increases the FoxM1 level (Krupczak-Hollis et al. 2003), which stimulates the cell cycle progression at both the G1/S- and G2/M-phase transitions (Wang et al. 2001, 2002a,b, 2005, Major et al. 2004). Progression through the cell cycle is regulated by the temporal activation of multiple families of Cdk. Cdc25A, $\mathrm{Cdc} 25 \mathrm{~B}$, and $\mathrm{Cdc} 25 \mathrm{C}$ with phosphatase activities are involved in the activation of Cdks in a way that these enzymes dephosphorylate catalytic units of Cdks (Sebastian et al. 1993). Upon S-phase progression, Cdc25A phosphatase activates Cdk2-cyclin E by dephosphorylating inhibitory Cdk2 residues (Massague 2004). Progression through the 
G2/M transition requires the activation of the Cdk1-cyclin B complex through dephosphorylation and the activation of Cdk1 by the Cdc25B and Cdc25C phosphatases, the latter of which is activated by Polo-like kinase 1 phosphorylation (Barr et al. 2004). It is noteworthy that rhGH up-regulated mRNAs of $h$ FoxM1, $h$ Cdc25A, $h$-cyclin B1, $h$-cyclin D1, $h \mathrm{Cdk} 1$, and $h \mathrm{Cdk} 2$ in 6YG-hepatocytes, but not 46YMcounterparts. Thus, it can be said that GH activates cell cycle progression of $h$-hepatocytes as known in rodents. The phosphorylation levels of Janus activating kinase 2 and GHR complex were decreased with age of rats (Xu et al. 1995). In the present study we showed that 6YG-hepatocytes expressed $h$ GHR mRNA at much higher levels than 46YM-hepatocytes. This apparent age-dependent GH-expression level of $h$-hepatocytes should be tested in further studies with sufficient samples of donor hepatocytes for statistical treatments of the obtained results.

In this study we demonstrated usefulness of a $h$-hepatocytechimeric uPA/SCID mouse as an in vivo model to study effects of $\mathrm{GH}$ on the proliferation of $h$-hepatocytes. $h$-Hepatocyte-chimeric mice were also yielded using another type of immunodeficient and liver-injured mice obtained by crossing uPA-transgenic mice with mice whose recombinant activation gene-2 (RAG-2) had been deleted (Dandri et al., 2001). It is worthy of examining in the future whether the effects of $r h \mathrm{GH}$ on $h$-hepatocytes observed in the present study can be reproduced in this uPA/RAG-2 mouse model. As clearly demonstrated for GH-GHR binding in the present study, $h$-hepatocytes in mice could be deficient for other growth factors and cytokines due to problems in interspecies ligand-receptor interaction. However, this limitation of $h$-hepatocyte-chimeric mice will provide us opportunities to study the mechanism of their interactions in vivo using chimeric mice in place of human body as exemplified for $\mathrm{r} h \mathrm{GH}$ on $h$-hepatocytes in this study.

\section{Acknowledgements}

This study was supported by Cooperative Link of Unique Science and Technology for Economy Revitalization, Japan. We thank Y Yoshizane, H Kohno, Y Matsumoto, and S Nagai for breeding the mice and providing excellent technical assistance. The authors declare that there is no conflict of interest that would prejudice the impartiality of this scientific work.

\section{References}

Barr FA, Sillje HH \& Nigg EA 2004 Polo-like kinases and the orchestration of cell division. Nature Reviews. Molecular Cell Biology 5 429-440.

Bucher NL, Swaffield MN \& DiTroia JF 1964 The influence of age upon the incorporation of thymidine-2-C14 into the DNA of regenerating rat liver. Cancer Research 24 509-512.

Corpas E, Harman SM \& Blackman MR 1993 Human growth hormone and human aging. Endocrine Reviews 14 20-39.
Dandri M, Burda MR, Torok E, Pollok JM, Iwanska A, Sommer G, Rogiers X, Rogler CE, Gupta S, Will H et al. 2001 Repopulation of mouse liver with human hepatocytes and in vivo infection with hepatitis B virus. Hepatology 33 1005-1006.

Daughaday WH \& Rotwein P 1989 Insulin-like growth factors I and II. Peptide, messenger ribonucleic acid and gene structures, serum, and tissue concentrations. Endocrine Reviews 10 68-91.

Desbois-Mouthon C, Wendum D, Cadoret A, Rey C, Leneuve P, Blaise A, Housset C, Tronche F, Le Bouc Y \& Holzenberger M 2006 Hepatocyte proliferation during liver regeneration is impaired in mice with liverspecific IGF-1R knockout. FASEB Journal 20 773-775.

Emoto K, Tateno C, Hino H, Amano H, Imaoka Y, Asahina K, Asahara T \& Yoshizato K 2005 Efficient in vivo xenogeneic retroviral vector-mediated gene transduction into human hepatocytes. Human Gene Therapy 16 1168-1174.

Fausto N 2000 Liver regeneration. Journal of Hepatology 32 19-31.

Gronowski AM \& Rotwein P 1994 Rapid changes in nuclear protein tyrosine phosphorylation after growth hormone treatment in vivo. Journal of Biological Chemistry $2697874-7878$.

Gronowski AM, Zhonq Z, Wen Z, Thomas MJ, Darnell JE Jr \& Rotwein P 1995 In vivo growth hormone treatment rapidly stimulates the tyrosine phosphorylation and activation of Stat3. Molecular Endocrinology 9 171-177.

Herrington J, Smit LS, Schwartz J \& Carter-Su C 2000 The role of STAT proteins in growth hormone signaling. Oncogene 19 2585-2597.

Kelijman M 1991 Age-related alterations of the growth hormone/insulin-likegrowth-factor I axis. Journal of the American Geriatrics Society 39 295-307.

Krupczak-Hollis K, Wang X, Dennewitz MB \& Costa RH 2003 Growth hormone stimulates proliferation of old-aged regenerating liver through Forkhead Box m1b. Hepatology 38 1552-1562.

Livak KJ \& Schmittgen TD 2001 Analysis of relative gene expression data using real-time quantitative PCR and the $2^{-\Delta \Delta \mathrm{C}_{\mathrm{T}}}$ method. Methods 25 402-408.

Major ML, Lepe R \& Costa RH 2004 Forkhead Box M1B (FoxM1B) transcriptional activity requires binding of $\mathrm{Cdk} /$ cyclin complexes for phosphorylation-dependent recruitment of p300/CBP co-activators. Molecular and Cellular Biology 24 2649-2661.

Mars WM, Liu ML, Kitson RP, Goldfarb RH, Gabauer MK \& Michalopoulos GK 1995 Immediate early detection of urokinase receptor after partial hepatectomy and its implications for initiation of liver regeneration. Hepatology 21 1695-1701.

Massague J 2004 G1 cell-cycle control and cancer. Nature 432 298-306.

Meuleman P, Vanlandschoot P \& Leroux-Roels G 2003 A simple and rapid method to determine the zygosity of uPA-transgenic SCID mice. Biochemical and Biophysical Research Communications 308 375-378.

Michalopoulos GK \& DeFrances MC 1997 Liver regeneration. Science 276 60-66.

Pennisi PA, Kopchick JJ, Thorgeirsson S, LeRoith D \& Yakar S 2004 Role of growth hormone $(\mathrm{GH})$ in liver regeneration. Endocrinology 145 4748-4755

Sebastian B, Kakizuka A \& Hunter T 1993 Cdc25M2 activation of cyclindependent kinases by dephosphorylation of threonine-14 and tyrosine-15. PNAS 90 3521-3524.

Sjogren K, Liu JL, Blad K, Skrtic S, Vidal O, Wallenius V, LeRoith D, Tornell J, Isaksson OG, Jansson JO et al. 1999 Liver-derived insulin-like growth factor I (IGF-I) is the principal source of IGF-I in blood but is not required for postnatal body growth in mice. PNAS 96 7088-7092.

Souza SC, Frick GP, Wang X, Kopchick JJ, Lobo RB \& Goodman HM 1995 A single arginine residue determines species specificity of the human growth hormone receptor. PNAS 92 959-963.

Stocker E \& Heine WD 1971 Regeneration of liver parenchyma under normal and pathological conditions. Beiträge zur Pathologie 144 400-408.

Tateno C, Yoshizane Y, Saito N, Kataoka M, Utoh R, Yamasaki C, Tachibana A, Soeno Y, Asahina K, Hino H et al. 2004 Near completely humanized liver in mice shows human-type metabolic responses to drugs. American Journal of Pathology 165 901-912.

Taub R 1996 Liver regeneration 4: transcriptional control of liver regeneration. FASEB Journal 10 413-427. 
Tsuge M, Hiraga N, Takaishi H, Noguchi C, Oga H, Imamura M, Takahashi S, Iwao E, Fujimoto Y, Ochi $\mathrm{H}$ et al. 2005 Infection of human hepatocyte chimeric mouse with genetically engineered hepatitis B virus. Hepatology 42 1046-1054.

Wang X, Quail E, Hung NJ, Tan Y, Ye H \& Costa RH 2001 Increased levels of Forkhead box M1B transcription factor in transgenic mouse hepatocytes prevent age-related proliferation defects in regenerating liver. PNAS $\mathbf{9 8}$ $11468-11473$.

Wang X, Kiyokawa H, Dennewitz MB \& Costa RH 2002a The Forkhead Box M1B transcription factor is essential for hepatocyte DNA replication and mitosis during mouse liver regeneration. PNAS 99 16881-16886.

Wang X, Krupczak-Hollis K, Tan Y, Dennewitz MB, Adami GR \& Costa RH $2002 b$ Increased hepatic Forkhead Box M1B (FoxM1B) levels in old-aged mice stimulated liver regeneration through diminished $\mathrm{p} 27^{\mathrm{kip} 1}$ protein levels and increased Cdc25B expression. Journal of Biological Chemistry 277 44310-44316.

Wang IC, Chen YJ, Hughes D, Petrovic V, Major ML, Park HJ, Tan Y, Ackerson T \& Costa RH 2005 Forkhead Box M1 regulates the transcriptional network of genes essential for mitotic progression and genes encoding the SCF (Skp2-Cks1) ubiquitin ligase. Molecular and Cellular Biology 25 10875-10894.

Xu X, Bennett SA, Ingram RL \& Sonntag WE 1995 Decreases in growth hormone receptor signal transduction contribute to the decline in insulinlike growth factor I gene expression with age. Endocrinology 136 4551-4557.

Yakar S, Liu JL, Stannard B, Butler A, Accili D, Sauer B \& LeRoith D 1999 Normal growth and development in the absence of hepatic insulin-like growth factor I. PNAS 96 7324-7329.

Received in final form 3 June 2007

Accepted 7 June 2007

Made available online as an Accepted Preprint 12 June 2007 